\title{
openheart Frailty is associated with delirium and mortality after transcatheter aortic valve implantation
}

\author{
Patricia Assmann, ${ }^{1,2}$ Peter Kievit, ${ }^{3}$ Kees van der Wulp, ${ }^{3}$ Michel Verkroost, ${ }^{4}$ \\ Luc Noyez, ${ }^{4}$ Hans Bor, ${ }^{1}$ Yvonne Schoon ${ }^{5}$
}

To cite: Assmann $P$, Kievit $P$, van der Wulp $\mathrm{K}$, et al. Frailty is associated with delirium and mortality after transcatheter aortic valve implantation. Open Heart 2016;3:e000478. doi:10.1136/openhrt-2016000478

Received 19 May 2016 Revised 18 September 2016 Accepted 18 October 2016

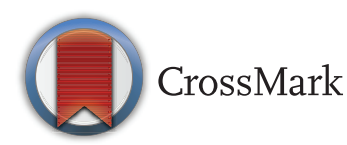

\footnotetext{
${ }^{1}$ Department of Primary and Elderly Care, Radboud University Medical Centre Nijmegen, The Netherlands '2ZG Care Group, Nijmegen, The Netherlands

${ }^{3}$ Department of Cardiology, Radboud University Medical Centre Nijmegen,

The Netherlands

${ }^{4}$ Department of Cardio-

Thoracic Surgery, Radboud University Medical Centre Nijmegen, The Netherlands ${ }^{5}$ Department of Geriatrics, Radboud University Medical Centre Nijmegen,

The Netherlands
}

Correspondence to Dr Patricia Assmann; p.assmann@zzgzorggroep.nl

\section{ABSTRACT}

Objective: We hypothesised that frailty assessment is of additional value to predict delirium and mortality after transcatheter aortic valve implantation (TAVI).

Methods: Observational study in 89 consecutive patients who underwent TAVI. Inclusion from November 2012 to February 2014, follow-up until April 2014. Measurement of the association of variables from frailty assessment and cardiological assessment with delirium and mortality after TAVI, respectively.

Results: Incidence of delirium after TAVI: 25/89 (28\%). Variables from frailty assessment protectively associated with delirium were: Mini Mental State Examination, (OR $0.79 ; 95 \% \mathrm{Cl} 0.65$ to $0.96 ; \mathrm{p}=0.02$ ), Instrumental Activities of Daily Living (OR $0.79 ; 95 \%$ $\mathrm{Cl} 0.63$ to $0.99 ; \mathrm{p}=0.04)$ and gait speed (OR 0.05; $95 \% \mathrm{Cl} 0.01$ to $0.50 ; p=0.01)$. Timed Up and Go was predictively associated with delirium (OR 1.14; $95 \% \mathrm{Cl}$ 1.03 to $1.26 ; p=0.01$ ). From cardiological assessment, pulmonary hypertension was protectively associated with delirium (OR $0.34 ; 95 \% \mathrm{Cl} 0.12$ to $0.98 ; \mathrm{p}=0.05$ ). Multivariate logistic analysis: Nagelkerke $R^{2}=0.359$, Mini Mental State Examination was independently associated with delirium. Incidence of mortality: 11/89 $(12 \%)$. Variables predictively associated with mortality were: the summary score Frailty Index (HR 1.66, 95\% $\mathrm{Cl} 1.06$ to 2.60; $p=0.03$ ), European System for Cardiac Operative Risk Evaluation (EuroSCORE) II (HR 1.14, $95 \% \mathrm{Cl} 1.06$ to $1.22 ; \mathrm{p}<0.001$ ) and complications (HR $4.81,95 \% \mathrm{Cl} 1.03$ to $22.38 ; p=0.05$ ). Multivariate Cox proportional hazards analysis: Nagelkerke $\mathrm{R}^{2}=0.271$, Frailty Index and EuroSCORE II were independently associated with mortality.

Conclusions: Delirium frequently occurs after TAVI. Variables from frailty assessment are associated with delirium and mortality, independent of cardiological assessment. Thus, frailty assessment may have additional value in the prediction of delirium and mortality after TAVI.

\section{INTRODUCTION}

Severe symptomatic aortic stenosis occurs in $3.4 \%$ of patients aged $>75$ years, ${ }^{1}$ for which the standard treatment is surgical aortic valve replacement. However, in patients with older

\section{KEY QUESTIONS}

What is already known about this subject?

- Severe aortic stenosis occurs in $3.4 \%$ of patients aged $>75$. Transcatheter aortic valve implantation (TAVI) is less invasive compared with the standard surgical procedure and may therefore be performed in elderly patients at high risk.

- Guidelines advocate to include frailty into the risk models for TAVI.

- Delirium frequently occurs after TAVI (12-53\%), is associated with mortality, morbidity and increased costs, whereas it is often unrecognised and may be preventable in $30-40 \%$ of cases.

- Previous studies showed no relation between frailty and delirium after TAVI.

What does this study add?

- To our best knowledge, this study is the first to investigate the association of objective frailty assessment with delirium in a specific group of patients after TAVI. This study reveals that from frailty assessment the separate variables: Mini Mental State Examination, Instrumental Activities of Daily Living, gait speed and Timed Up and Go are associated with delirium after TAVI. The summary score Frailty Index is associated with mortality, independent of cardiological assessment.

How might this impact on clinical practice?

- In elderly patients with symptomatic aortic stenosis, frailty assessment may improve identification of patients at high risk for delirium and mortality, and thus improve treatment stratification with proactive implementation of preventive strategies.

age and left ventricular dysfunction surgery is often denied. ${ }^{2}$

Transcatheter aortic valve implantation (TAVI) has been developed as an alternative to surgical aortic valve replacement in highrisk patients with symptomatic aortic valve stenosis. TAVI has been shown to be superior 
to medical treatment, ${ }^{3}{ }^{4}$ while survival rates are similar or even higher compared with surgical aortic valve replacement. ${ }^{5}{ }^{6}$ Nevertheless, in these high-risk elderly patients, morbidity and mortality after TAVI is substantial; 1-year mortality was $14.2-19 \%$ and 2-year mortality was 33.9$43.3 \% .^{3-6}$ Although reduction of mortality is noted, ${ }^{7}$ adequate risk assessment in this population is mandatory.

The European System for Cardiac Operative Risk Evaluation (EuroSCORE) is widely used to predict operative mortality in cardiac surgery. However, this model was developed and validated in a standard surgical risk population. Frailty, defined as a syndrome of impaired physiological reserve and decreased resistance to stressors, has been shown useful to identify patients at increased risk of mortality after TAVI. ${ }^{8-10}$ Therefore, a risk model for elderly and high-risk patients undergoing TAVI should comprise frailty. ${ }^{11-13}$

Delirium frequently occurs after TAVI; incidence $12-53 \%{ }^{14-16}$ In-hospital delirium is associated with mortality, morbidity and increased costs, whereas it is often unrecognised and may be preventable in $30-40 \%$ of cases. ${ }^{17}$ As a potent indicator of patients' safety, delirium provides a target for system-wide process improvements. ${ }^{17}$ Frailty has been shown to be associated with postoperative delirium. ${ }^{19}{ }^{20}$ In patients referred for TAVI, predictive models for delirium may be useful to identify high-risk patients, to allow treatment stratification and proactive implementation of preventive strategies. ${ }^{17}{ }^{21}$ Investigations were performed to identify risk factors associated with delirium after cardiac surgery, including TAVI. ${ }^{14-16} 20$ Previous investigators found no relation between frailty and delirium after TAVI, however, in these studies variables of frailty were not objectively assessed. ${ }^{15} 16$

The aim of this study is to reveal the value of objective frailty assessment, in addition to cardiological assessment, to identify variables associated with delirium and mortality in patients undergoing TAVI.

\section{METHODS}

\section{Study setting, participants and treatment assignment}

The study was conducted in a single tertiary referral centre. Between November 2012 and February 2014 data from 305 patients with severe symptomatic aortic valve stenosis referred for aortic valve replacement were reviewed by a heart team consisting of a cardiothoracic surgeon, an interventional cardiologist and a general or imaging cardiologist. Based on the available cardiological data, 177 patients were primarily considered candidates for surgical aortic valve replacement and underwent routine preoperative screening. The remaining 128 patients were considered as high-risk or potentially frail. These patients were referred to a specialised pre-TAVI outpatient clinic, where patients were assessed by a multidisciplinary team consisting of a cardiac anaesthesiologist, a cardiac surgeon, a cardiologist and a geriatrician. Based on consensus from this team and the patient, 91 patients were assigned to TAVI, 18 to surgical aortic valve replacement and 19 to medical treatment, figure 1 . Two patients assigned to TAVI died before the procedure was performed.

\section{Baseline measures}

\section{Cardiological assessment}

In the heart team patients were discussed based on reported patient history and routine cardiological examination including echocardiography, coronary angiography and additional imaging with respect to access site and suitability for TAVI, when appropriate. In addition, EuroSCORE I and EuroSCORE II variables were obtained (age, gender, renal impairment, extracardiac arteriopathy, subjective poor mobility, previous cardiac surgery, chronic lung disease, diabetes on insulin, New York Heart Association (NYHA) classification, left ventricular function, pulmonary hypertension).

At the pre-TAVI outpatient clinic, cardiological assessment consisted of patient history, physical examination and ECG.

\section{Frailty assessment}

Geriatric assessment consisted of patient history, (hetero)anamnesis, medication review and the following specific instruments for frailty assessment: Mini Mental State Examination (range 0-30, with higher scores indicating better cognitive status), ${ }^{22}$ Basic Activities of Daily Living (range 0-20, with higher scores indicating better functional performance) and Instrumental Activities of Daily Living (range 0-8, with higher scores indicating better functional performance), mobility: gait speed $(\mathrm{m} / \mathrm{s}$, velocity measured over a distance of $4 \mathrm{~m}$, with higher scores indicating better mobility) and/or Timed Up and Go (TUG) test (seconds, with lower scores indicating better mobility), Mini Nutritional Assessment (range 0-14, with scores below 12 indicating risk of malnutrition). Frailty Index (range $0-5$, with higher scores indicating frailer status) was calculated as a summary score from these baseline components: 1 point was assigned for Mini Mental State Examination $\leq 27$; Basic Activities of Daily Living $\geq 1$ limited activity; Instrumental Activities of Daily Living $\geq 1$ limited activity; Mini Nutritional Assessment <12; impaired mobility: when neither gait speed over $4 \mathrm{~m} \geq 0.75 \mathrm{~m} / \mathrm{s}$ nor $\mathrm{TUG}<12.5 \mathrm{~s}$, respectively. Clinical judgement from the geriatrician about frailty and risk for delirium were noted as variables, in addition to the objective frailty assessment, as obtained by this geriatrician.

\section{TAVI procedure}

All procedures were performed under general anaesthesia; oxazepam and paracetamol were given as premedication 1 hour prior to transfer to the catheterisation laboratory. General anaesthesia was induced using sufentanil and midazolam. The Medtronic CoreValve (Medtronic, Minneapolis, Minnesota, USA) was used, with surgical vascular access through the left subclavian artery, which is the access site of choice in our centre. 


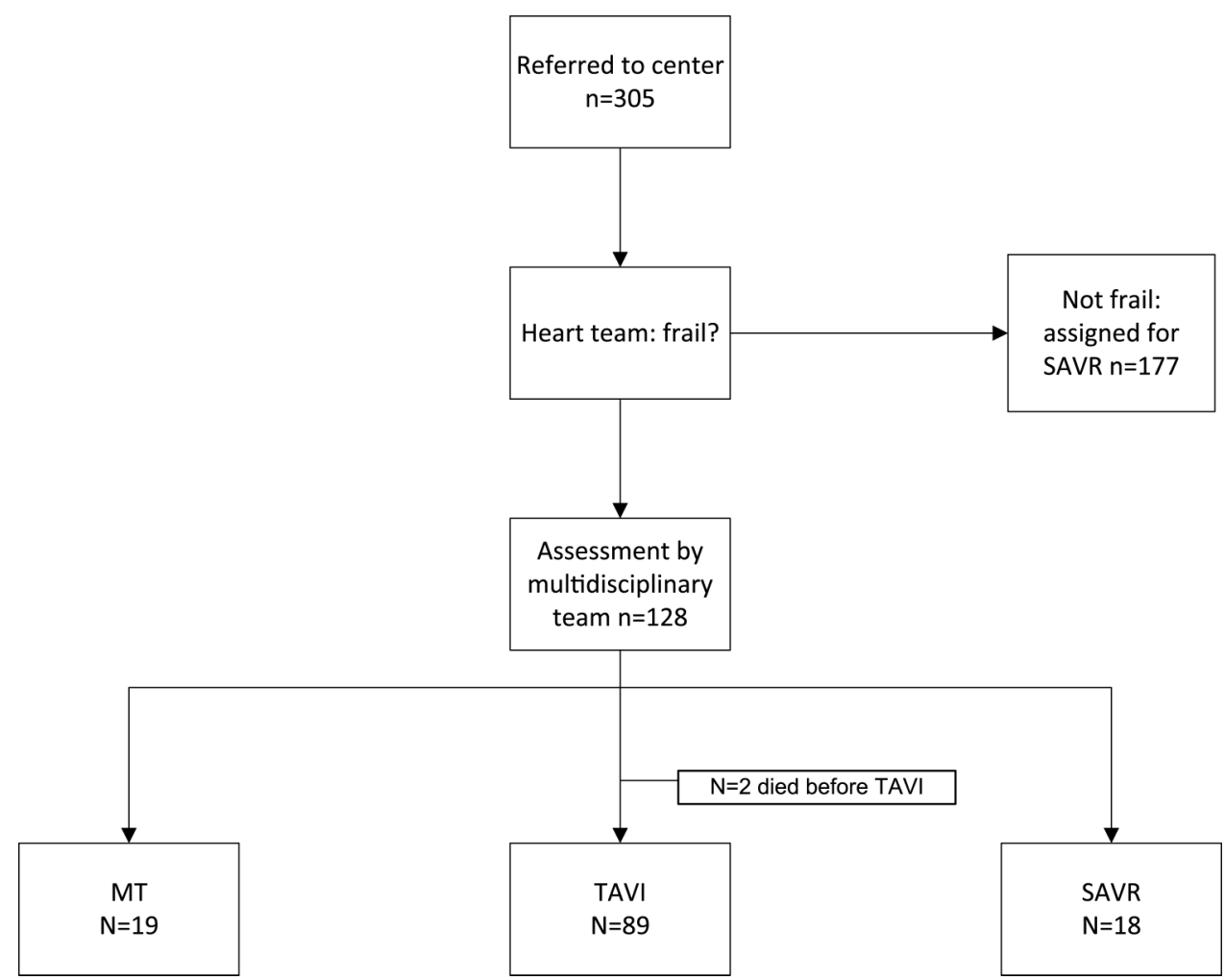

Figure 1 Flow chart of procedure for treatment assignment. MT, medical therapy; SAVR, surgical aortic valve replacement; $\mathrm{TAVI}$, transcatheter aortic valve implantation.

After TAVI, patients were admitted to the intensive care unit for the first day, weaning from ventilation within 2-4 hours after admission, with subsequent transfer to the coronary care unit the following day.

\section{Outcomes}

Incidence of delirium

The hospital has a multidisciplinary guideline for prevention, diagnosis and treatment of delirium, including postprocedural Delirium Observation Scales and observations from attending physicians and nurses. Delirium was defined according to the Diagnostic and Statistical Manual of Mental Disorders, Fourth Edition (DSM-IV) comprising the following features: (1) disturbance in consciousness with reduced ability to focus, sustain, or shift attention; (2) change in cognition or the development of a perceptual disturbance; (3) acute onset and fluctuating course and (4) evidence of an organic aetiological factor. A geriatric consultation team assessed the diagnosis delirium on a daily basis during hospital stay.

\section{Incidence of mortality}

All-cause mortality was assessed, based on registration of in-hospital mortality, supplemented with data from follow-up, the hospital electronic patient file, and by calling the general practitioner to check for patients lost to follow-up. Mortality data were obtained until 1 April 2014.

\section{Data analysis}

Univariate logistic regression analysis was performed to identify a relation of variables with the incidence of delirium. Univariate Cox proportional hazards regression analysis was performed to identify a relation between the variables and all-cause mortality, measured from the date of TAVI until mortality or end of follow-up (days). Multivariate logistic regression analysis was performed by using age and the variables related with incidence of delirium and mortality, as measured with univariate logistic regression analysis and univariate Cox proportional hazards regression analysis, respectively, with a significance level $\mathrm{p}<0.05$. When variables were mutually strongly related, as expected from the nature of the variables and confirmed by Pearson's correlation for interval/ratio variables or Spearman's correlation for ordinal variables, a variable was selected for exclusion from the multivariate logistic regression analysis. The quality of the multivariate regression and Cox proportional hazards models is provided with Nagelkerke $R^{2}$. For variables significantly related with delirium or mortality, by univariate analysis, the independent samples Student's t-test was used for interval variables and the $\chi^{2}$ test for categorical variables, to assess differences in mean score or proportion in patients with or without delirium and mortality, respectively. All statistical analyses were performed using SPSS 22.0 (IBM Corp., Armonk, New York, USA). 


\section{RESULTS}

\section{Incidence and severity of delirium}

Baseline characteristics and clinical outcome during follow-up are shown in table 1 .

The incidence of postprocedural delirium was in 25/ $89(28 \%)$ patients, table 1 . The median onset of delirium was on day 2 (IQR 1.5-2.5 days), with a median duration of 2 days (IQR 0.5-3.5 days). Haloperidol was given to $29 / 89$ (33\%) patients; it was prescribed for treatment of delirium in 24 patients and for prevention of delirium in 5 patients with a history of delirium, of whom 1 patient developed a postprocedural delirium. The median total amount of haloperidol given for treatment of delirium was $3.5 \mathrm{mg}$ (IQR 2.5-4.5 mg) over a median period of 2.5 days (IQR $1.0-4.0$ days).

\section{Variables associated with delirium after TAVI—univariate analysis}

Variables significantly associated with delirium were: pulmonary hypertension (OR per unit change 0.43 ; 0.19 to
0.96; $\mathrm{p}=0.04$ ), Mini Mental State Examination (OR 0.79; $95 \%$ CI 0.65 to $0.96 ; \mathrm{p}=0.02)$, impaired Instrumental Activities of Daily Living (OR 0.79; 95\% CI 0.63 to 0.99 ; $\mathrm{p}=0.04$ ), gait speed (OR $0.05 ; 95 \%$ CI 0.01 to 0.50 ; $\mathrm{p}=0.01$ ), TUG (OR 1.14; 95\%; CI 1.03 to $1.26 ; \mathrm{p}=0.01$ ) and clinical judgement of frailty (OR 3.10; 95\% CI 1.14 to $8.46 ; \mathrm{p}=0.03$ ), table 2 . Thus, patients with lower systolic pulmonary artery pressure, lower Mini Mental State Examination score, lower Instrumental Activities of Daily Living performance, lower gait speed, higher TUG score or with a clinical judgement of frailty were at higher risk to develop postprocedural delirium.

\section{Variables associated with mortality after TAVI—univariate Cox proportional hazards regression analysis}

Within the first 30 days after TAVI 5/89 patients died $(5.6 \%)$. After a median follow-up of 195 days (IQR 69321 days) mortality was $11 / 89(12.4 \%)$, table 1 .

Variables significantly associated with mortality, measured by univariate regression analysis were: EuroSCORE I (HR

Table 1 Baseline characteristics and clinical outcome during follow-up

\begin{tabular}{|c|c|}
\hline \multicolumn{2}{|l|}{ Transcatheter aortic valve implantation $n=89$} \\
\hline \multicolumn{2}{|l|}{ Baseline—cardiological assessment } \\
\hline Age, mean (SD), year & $80.4(6.3)$ \\
\hline Weight, mean (SD), kg & $73.6(15.0)$ \\
\hline Body mass index, mean (SD), $\mathrm{kg} / \mathrm{m}^{2}$ & $26.9(4.9)$ \\
\hline Gender, male, n (\%) & $38(43)$ \\
\hline Renal impairment $<50 \mathrm{~mL} / \mathrm{min} / 1.73 \mathrm{~m}^{2}, \mathrm{n}(\%)$ & $47(53)$ \\
\hline Extracardiac arteriopathy, $\mathrm{n}(\%)$ & $24(27)$ \\
\hline Subjective poor mobility, $\mathrm{n}(\%)$ & $8(9)$ \\
\hline Previous cardiac surgery, $\mathrm{n}(\%)$ & $1(1)$ \\
\hline Chronic lung disease, $\mathrm{n}(\%)$ & $20(22)$ \\
\hline Diabetes on insulin, $\mathrm{n}(\%)$ & $24(27)$ \\
\hline New York Heart Association (classification) III or IV, n (\%) & $77(87)$ \\
\hline Ejection fraction $\leq 30 \%, \mathrm{n}(\%)$ & $5(6) n=78$ \\
\hline Pulmonary hypertension $>30 \mathrm{~mm} \mathrm{Hg}, \mathrm{n}(\%)$ & $55(72) n=76$ \\
\hline EuroSCORE I, mean (SD) & $15.9(9.8)$ \\
\hline EuroSCORE II, mean (SD) & $5.4(5.0)$ \\
\hline Aortic valve area, mean (SD), $\mathrm{cm}^{2}$ & $0.72(0.25)$ \\
\hline Aortic valve peak gradient, mean (SD), $\mathrm{mm} \mathrm{Hg}$ & 75.7 (22.6) \\
\hline \multicolumn{2}{|l|}{ Baseline-frailty assessment } \\
\hline Mini Mental State Examination (range 0-30), mean (SD) & $27.0(2.5)$ \\
\hline Basic Activities of Daily Living (range 0-20), mean (SD) & $18.5(1.8)$ \\
\hline Instrumental Activities of Daily Living (range $0-8$ ), mean (SD) & $6.4(2.0)$ \\
\hline Gait speed, mean (SD), $\mathrm{m} / \mathrm{s}$ & $0.84(0.3)$ \\
\hline Timed Up and Go, mean (SD), seconds & $12.8(6.2)$ \\
\hline Mini Nutritional Assessment (range 0-14), mean (SD) & $11.7(2.5)$ \\
\hline Frailty Index (range 0-5), mean (SD) & $2.38(1.47)$ \\
\hline Clinical judgement frail, $n(\%)$ & $47(53)$ \\
\hline Clinical judgement high risk for delirium, n (\%) & $65(73)$ \\
\hline \multicolumn{2}{|l|}{ Clinical outcome } \\
\hline TIA/CVA, n (\%) & $1(1)$ \\
\hline Renal failure, $\mathrm{n}(\%)$ & $0(0)$ \\
\hline Gastric bleeding, n (\%) & $1(1)$ \\
\hline Vascular complications, n (\%) & $3(3)$ \\
\hline Postprocedural incidence of delirium, in-hospital, $n(\%)$ & $25(28)$ \\
\hline Mortality (all-cause), median follow-up 195 days (IQR 69-321 days), n (\%) & $11(12)$ \\
\hline
\end{tabular}


Table 2 Variables associated with delirium and mortality after transcatheter aortic valve implantation (TAVI)

\begin{tabular}{|c|c|c|c|c|c|c|}
\hline \multirow[b]{2}{*}{ Univariate regression analysis } & \multicolumn{3}{|c|}{$\begin{array}{l}\text { Variables associated with } \\
\text { delirium }\end{array}$} & \multicolumn{3}{|c|}{$\begin{array}{l}\text { Variables associated with } \\
\text { mortality }\end{array}$} \\
\hline & $\overline{\text { OR }}$ & $95 \% \mathrm{Cl}$ & p Value & HR & $95 \% \mathrm{Cl}$ & p Value \\
\hline \multicolumn{7}{|l|}{ Baseline cardiological assessment } \\
\hline Age, year & 1.05 & 0.97 to 1.14 & 0.22 & 0.98 & 0.89 to 1.07 & 0.62 \\
\hline Weight, kg & 0.99 & 0.96 to 1.02 & 0.58 & 0.98 & 0.94 to 1.03 & 0.39 \\
\hline Body mass index, $\mathrm{kg} / \mathrm{m}^{2}$ & 1.02 & 0.93 to 1.12 & 0.65 & 0.95 & 0.83 to 1.09 & 0.46 \\
\hline Gender, male & 0.68 & 0.26 to 1.76 & 0.43 & 0.47 & 0.12 to 1.76 & 0.26 \\
\hline Renal impairment $<50 \mathrm{~mL} / \mathrm{min} / 1.73 \mathrm{~m}^{2}$ & 0.61 & 0.24 to 1.55 & 0.30 & 2.21 & 0.59 to 8.34 & 0.24 \\
\hline Extracardiac arteriopathy & 0.59 & $0.19-1.81$ & 0.36 & 1.51 & 0.44 to 5.16 & 0.51 \\
\hline Chronic lung disease & 1.75 & 0.52 to 5.87 & 0.37 & 1.99 & 0.58 to 6.79 & 0.27 \\
\hline Diabetes on insulin & 1.24 & 0.43 to 3.60 & 0.69 & 1.58 & 0.46 to 5.40 & 0.47 \\
\hline New York Heart Association (classification) III or IV & 0.80 & 0.21 to 3.37 & 0.36 & 0.77 & 0.17 to 3.56 & 0.73 \\
\hline Subjective poor mobility & 1.61 & 0.35 to 7.30 & 0.54 & 0.04 & 0.00 to 439.11 & 0.50 \\
\hline Ejection fraction $\leq 30 \%$ & 1.65 & 0.26 to 10.60 & 0.60 & 1.23 & 0.16 to 9.67 & 0.84 \\
\hline Pulmonary hypertension $(0-30 / 31-55 />55 \mathrm{~mm} \mathrm{Hg})$ & 0.43 & 0.19 to 0.96 & $0.04^{*}$ & 1.30 & 0.49 to 3.49 & 0.60 \\
\hline EuroSCORE I & 1.00 & 0.95 to 1.05 & 0.97 & 1.08 & 1.03 to 1.13 & $0.002^{*}$ \\
\hline EuroSCORE II & 1.00 & 0.91 to 1.10 & 0.95 & 1.14 & 1.06 to 1.22 & $<0.001^{*}$ \\
\hline Aortic valve area, $\mathrm{cm}^{2}$ & 1.58 & 0.19 to 12.90 & 0.67 & 0.11 & 0.01 to 1.95 & 0.13 \\
\hline Aortic valve peak gradient, $\mathrm{mm} \mathrm{Hg}$ & 1.00 & 0.97 to 1.02 & 0.79 & 0.98 & 0.95 to 1.02 & 0.31 \\
\hline \multicolumn{7}{|l|}{ Baseline frailty assessment } \\
\hline Mini Mental State Examination, range 0-30 & 0.79 & 0.65 to 0.96 & $0.02^{*}$ & 0.98 & 0.77 to 1.25 & 0.89 \\
\hline Basic Activities of Daily Living, range 0-20 & 1.00 & 0.78 to 1.30 & 0.98 & 0.86 & 0.66 to 1.12 & 0.26 \\
\hline Instrumental Activities of Daily Living, range $0-8$ & 0.79 & 0.63 to 0.99 & $0.04^{*}$ & 0.92 & 0.71 to 1.20 & 0.53 \\
\hline Gait speed, $\mathrm{m} / \mathrm{s}$ & 0.05 & 0.01 to 0.50 & $0.01^{*}$ & 0.11 & 0.01 to 1.43 & 0.09 \\
\hline Timed Up and Go, seconds & 1.14 & 1.03 to 1.26 & $0.01^{*}$ & 1.04 & 0.94 to 1.16 & 0.46 \\
\hline Mini Nutritional Assessment, range $0-14$ & 0.99 & 0.82 to 1.20 & 0.91 & 0.92 & 0.74 to 1.14 & 0.44 \\
\hline Frailty Index, range $0-5$ & 1.25 & 0.90 to 1.73 & 0.18 & 1.66 & 1.06 to 2.60 & $0.03^{*}$ \\
\hline Clinical judgement frailty, 0-1 & 3.10 & 1.14 to 8.46 & $0.03^{*}$ & 3.92 & 0.85 to 18.16 & 0.08 \\
\hline Clinical judgement high risk for delirium, $0-1$ & 2.39 & 0.72 to 7.87 & 0.15 & 1.48 & 0.32 to 6.88 & 0.62 \\
\hline \multicolumn{7}{|l|}{ Postoperative } \\
\hline Complications & 1.77 & 0.28 to 11.27 & 0.55 & 4.81 & 1.03 to 22.38 & $0.05^{\star}$ \\
\hline Incidence of delirium & & & & 1.06 & 0.28 to 4.00 & 0.93 \\
\hline
\end{tabular}

1.08 ; $95 \%$ CI 1.03 to $1.13 ; \mathrm{p}=.002$ ), EuroSCORE II (HR $1.14 ; 95 \%$ CI 1.06 to $1.22 ; \mathrm{p}<0.001$ ), Frailty Index (HR 1.66 ; $95 \%$ CI 1.06 to 2.60 ; $\mathrm{p}=.03$ ) and postoperative complications (HR 4.81; 95\% CI 1.03 to 22.38; $\mathrm{p}=.05$ ), table 2.

\section{Variables associated with delirium after TAVI- multivariate logistic regression analysis}

Clinical judgement of frailty is a subjective interpretation of frailty, obtained by a geriatrician with access to the results of frailty assessment and thus correlated with the separate variables (Instrumental Activities of Daily Living, $r=0.44$; gait speed, $r=0.53$; TUG, $r=0.49$ ) and with the objective summary score Frailty Index $(\mathrm{r}=0.59)$. Furthermore, gait speed and TUG are strongly correlated $(r=0.73)$, whereas gait speed was significantly related to Mini Mental State Examination ( $\mathrm{r}=0.31)$. Therefore, we performed multivariate regression analysis after exclusion of clinical judgement of frailty and gait speed, table 3. Quality of the model, Nagelkerke $\mathbf{R}^{2}=0.359$, Mini Mental State Examination was independently associated with delirium, table 3 .
Variables associated with mortality after TAVImultivariate Cox proportional hazards regression analysis

EuroSCORE II is the renewed version of EuroSCORE I, partly consisting of the same variables. EuroSCORE I and EuroSCORE II are strongly correlated ( $\mathrm{r}=0.86)$. Therefore, multivariate Cox proportional hazard regression analysis was performed after exclusion of EuroSCORE I, Quality of the model, Nagelkerke $\mathrm{R}^{2}=0.271$, revealing Frailty Index and EuroSCORE II as independently associated with mortality table 3 .

\section{Mean values variables associated with delirium and mortality}

Mean values for those variables significantly associated with delirium and mortality are presented for the groups with or without the occurrence of delirium and mortality, respectively, in table 4 .

Three of the 25 patients with delirium died $(12 \%)$ versus 8 of the 64 patients without delirium (12.5\%, $\mathrm{p}=\mathrm{ns})$. We found no relation between delirium and mortality. 
Table 3 Variables associated with delirium and mortality after transcatheter aortic valve implantation (TAVI), multivariate logistic regression analysis and Cox proportional hazards regression analysis

\begin{tabular}{|c|c|c|c|}
\hline Delirium & OR & $95 \% \mathrm{Cl}$ & $\begin{array}{l}p \text { Value } \\
R^{2}=0.359\end{array}$ \\
\hline Age & 1.04 & 0.93 to 1.17 & 0.47 \\
\hline Pulmonary hypertension & 0.31 & 0.10 to 1.04 & 0.06 \\
\hline Mini Mental State Examination & 0.73 & 0.53 to 0.99 & $0.04^{*}$ \\
\hline Instrumental Activities of Daily Living & 1.30 & 0.81 to 2.10 & 0.28 \\
\hline Timed up and Go & 1.15 & 0.99 to 1.34 & 0.08 \\
\hline Mortality & HR & $95 \% \mathrm{Cl}$ & $\begin{array}{l}p \text { Value } \\
R^{2}=0.271\end{array}$ \\
\hline Age & 0.94 & 0.84 to 1.06 & 0.32 \\
\hline Frailty Index & 1.82 & 1.04 to 3.18 & $0.04^{\star}$ \\
\hline EuroSCORE II & 1.13 & 1.05 to 1.22 & $0.002^{*}$ \\
\hline Complications & 4.31 & 0.89 to 20.95 & 0.07 \\
\hline
\end{tabular}

Table 4 Mean values (SD) for the variables significantly associated with delirium and mortality for the groups with or without the occurrence of delirium and mortality, respectively

\begin{tabular}{|c|c|c|c|}
\hline Delirium & No, $n=64$ & Yes, $n=25$ & p Value \\
\hline Pulmonary hypertension >30 mm Hg, n (\%) & $42 / 53(79)$ & $13 / 23(57)$ & $0.04^{*}$ \\
\hline Mini-Mental State Examination, mean (SD), (range 0-30) & $27.5(2.3)$ & $26.0(2.6)$ & $0.01^{*}$ \\
\hline Instrumental Activities of Daily Living, mean (SD), (range 0-8) & $6.7(1.7)$ & $5.6(2.5)$ & 0.07 \\
\hline Gait speed, mean (SD), m/s & $0.9(0.3)$ & $0.7(0.3)$ & $<0.01^{*}$ \\
\hline Timed Up and Go, mean (SD), seconds & $11.5(4.7)$ & $16.6(8.5)$ & $0.03^{*}$ \\
\hline Mortality & No, $n=78$ & Yes, $n=11$ & p Value \\
\hline Frailty Index, mean (SD) & $2.2(1.4)$ & $3.4(1.6)$ & $0.02^{*}$ \\
\hline EuroSCORE I, mean (SD) & $14.6(8.8)$ & $24.7(12.7)$ & $0.00^{*}$ \\
\hline EuroSCORE II, mean (SD) & $4.8(3.8)$ & $10.3(9.1)$ & $0.00^{*}$ \\
\hline Complications, n (\%) & $3(3.8)$ & 2 (18.2) & 0.27 \\
\hline
\end{tabular}

\section{DISCUSSION}

To our best knowledge, this study is the first to reveal a relation between objective frailty assessment with delirium in a specific group of patients after TAVI.

The finding that this relation was independent from cardiological assessment (table 3) suggests that frailty assessment may have additional value, by identifying patients at increased risk of delirium after TAVI.

Previous investigators found frailty related to delirium after cardiac surgery. ${ }^{20}$ However, in contrast to our study, Eide $e t a l^{15}$ found no relation between frailty and delirium after TAVI. The differences found in our study compared with the study from Eide et $a l^{15}$ may be related to differences in study design: (1) our study population is specific to TAVI, while their population includes patients after TAVI or surgical aortic valve replacement, (2) the number of patients after TAVI in our study group is higher, (3) our study group comprises consecutive patients, whereas their study group is restricted to octogenarians and (4) our study uses frailty assessment, with various separate variables, instead of one combined variable for frailty, in addition to Mini Mental State Examination. Our finding that cognitive function was related to delirium is in accordance with previous findings. ${ }^{15} 23$

The finding in our study that pulmonary hypertension was protectively associated with delirium was unexpected. Abawi et $a l^{16}$ found no significant relation between pulmonary hypertension and delirium after TAVI, whereas Eide et $a l^{15}$ provide no results for the variable pulmonary hypertension. The protective association between pulmonary hypertension and delirium is not easily explained and may be the result of the selection of frail patients to undergo TAVI, even in the absence of high cardiac risk. This argumentation is supported by the predictive association between frailty variables and delirium, while cardiac risk, as expressed in the EuroSCORE, is not associated with delirium. Further research on this subject is warranted.

In contrast to previous studies, we found no relation between postprocedural complications and delirium. ${ }^{16}$ 
The association of variables from frailty assessment with delirium is found in our study, even after selection of patients, which procedure tends to exclude patients with lower and higher risk factors. In our selection process patients with lower and higher risk were assigned to surgical aortic valve replacement and medical treatment, respectively. This selection process may explain the absence of a substantial association of age with delirium in our study, in contrast to observations in other studies. ${ }^{24}$ In addition, we found no substantial association of weight and body mass index with delirium, in contrast to Smulter et $a l^{25}$ Furthermore, they found no relation between impaired Mini Mental State Examination and delirium after cardiac surgery. ${ }^{25}$ However, they used Mini Mental State Examination both as a diagnostic tool and predictive factor for delirium, which may have been a confounding factor.

The incidence of delirium after TAVI in our study (28.1\%) is comparable to the incidence reported by previous studies examining delirium after TAVI $(12-53 \%)^{14} 15$ or cardiac surgery $(26-66 \%) .^{24-27}$ The observed incidence of delirium in our study may have been influenced by several factors: (a) transfer of the patient (from intensive care unit to cardiac care unit), (b) general anaesthesia, (c) strict patient follow-up by the geriatric consultation team and (d) preventive guidelines. Although delirium after cardiac surgery is common, previous investigators show that the incidence of delirium will be easily under-recognised clinically, without an appropriate strategy for diagnosis. ${ }^{23}$ Thus, a low incidence of delirium after TAVI reported by others $(11.5 \%)^{28}$ may have resulted from under-recognition. Considering the high incidence of delirium and the impact on morbidity and costs, the need for prevention of delirium after TAVI is amplified.

In our study variables from frailty assessment and cardiological assessment were independently associated with mortality (table 3 ), which suggests that frailty assessment may have additional value to the prediction of mortality after TAVI, in accordance with previous studies. ${ }^{8-10}$

The absence of a relation between the incidence of delirium and mortality after TAVI in our study, in contrast to previous studies, ${ }^{16}{ }^{17}$ is not conclusive, due to the limited absolute number of patients with delirium and mortality. However, in our study, accurate diagnosis followed by treatment of delirium may have resulted in reduced mortality after delirium.

\section{Limitations}

The absolute number of patients studied with the events delirium or mortality after TAVI is limited. However, analysis of this limited number of patients still provides valuable conclusions with regard to variables associated with delirium and mortality.

This study on association of frailty assessment with delirium and mortality is analysed in a selected population, whereas the selection procedure for treatment assignment is based on multidisciplinary decisionmaking, which may have been influenced by the same frailty assessment. However, since selection may have led to exclusion of patients with the more extreme values, the associations found may be underestimated, not overestimated.

Owing to multiple testing some caution should be used when interpreting the findings of the multiple univariate tests as there may be a risk of an inflated type I error rate, considering the large number of tests in the analysis. However, subject knowledge corroborates and further research may corroborate our findings.

The incidence of delirium in our study population may have been influenced by general anaesthesia, routinely performed in TAVI procedures in our centre with primarily subclavian access, whereas local anaesthesia is performed in other centres. In addition, the access site may have influenced the incidence of delirium, as previous investigators showed difference in incidence of delirium related to the access site of the TAVI procedure (transfemoral vs transapical). ${ }^{14}$ Moreover, the preventive use of haloperidol in 5/89 patients may have influenced the incidence of delirium. However, previous investigators found no effect of haloperidol in prevention of postoperative delirium. ${ }^{29}$

\section{CONCLUSIONS}

Delirium frequently occurs after TAVI. Variables from frailty assessment are associated with delirium, independent from cardiological assessment: Mini Mental State Examination, Instrumental Activities of Daily Living, gait speed and TUG. The summary score Frailty Index is associated with mortality, independent from cardiological assessment. Thus, frailty assessment may have additional value in the prediction of delirium and mortality after TAVI. Therefore, the cardiologist might consider involvement of a geriatrician for risk assessment in the selection of patients for TAVI. Further study is required in a broader range of patients.

Acknowledgements The authors gratefully acknowledge Helmut Gehlmann, MD, and Marleen van Wely, MD, interventional cardiologists, Radboud University Medical Centre, Department of Cardiology, for conducting the TAVI procedures.

Contributors PA made substantial contribution to the study concept and design; acquisition, analysis and interpretation of data; drafting of the article; revising repeatedly; and gave final approval of the version to be published. PK and YS made substantial contribution to the study concept and design; acquisition, analysis and interpretation of data; revising of the article critically for important intellectual content; and gave final approval of the version to be published. KvdW, MV and LNmade substantial contribution to acquisition of data; revising of the article critically for important intellectual content; and gave final approval of the version to be published. HBmade substantial contribution to analysis and interpretation of data; revising of the article critically for important intellectual content; and gave final approval of the version to be published.All authors agree to be accountable for all aspects of the work in ensuring that questions related to the accuracy or integrity of any part of the work are appropriately investigated and resolved.

Competing interests None declared. 
Provenance and peer review Not commissioned; internally peer reviewed.

Data sharing statement No additional data are available.

Open Access This is an Open Access article distributed in accordance with the Creative Commons Attribution Non Commercial (CC BY-NC 4.0) license, which permits others to distribute, remix, adapt, build upon this work noncommercially, and license their derivative works on different terms, provided the original work is properly cited and the use is non-commercial. See: http:// creativecommons.org/licenses/by-nc/4.0/

\section{REFERENCES}

1. Osnabrugge RL, Mylotte D, Head SJ, et al. Aortic stenosis in the elderly: disease prevalence and number of candidates for transcatheter aortic valve replacement: a meta-analysis and modeling study. J Am Coll Cardiol 2013;62:1002-12.

2. lung $B$, Cachier A, Baron G, et al. Decision-making in elderly patients with severe aortic stenosis: why are so many denied surgery? Eur Heart J 2005;26:2714-20.

3. Leon MB, Smith CR, Mack M, et al. Transcatheter aortic-valve implantation for aortic stenosis in patients who cannot undergo surgery. N Engl J Med 2010;363:1597-607.

4. Makkar RR, Fontana GP, Jilaihawi $\mathrm{H}$, et al. Transcatheter aortic-valve replacement for inoperable severe aortic stenosis. N Engl J Med 2012;366:1696-704.

5. Kodali SK, Williams MR, Smith CR, et al. Two-year outcomes after transcatheter or surgical aortic-valve replacement. N Engl J Med 2012;366:1686-95.

6. Adams DH, Popma JJ, Reardon MJ, et al. Transcatheter aortic-valve replacement with a self-expanding prosthesis. $N$ Engl $J$ Med 2014;370:1790-8.

7. Beohar N, Kirtane AJ, Blackstone E, et al. Trends in complications and outcomes of patients undergoing transfemoral transcatheter aortic valve replacement: experience from the PARTNER continued access registry. JACC Cardiovasc Interv 2016;9:355-63.

8. Green P, Woglom AE, Genereux P, et al. The impact of frailty status on survival after transcatheter aortic valve replacement in older adults with severe aortic stenosis: a single-center experience. JACC Cardiovasc Interv 2012;5:974-81.

9. Stortecky S, Schoenenberger AW, Moser A, et al. Evaluation of multidimensional geriatric assessment as a predictor of mortality and cardiovascular events after transcatheter aortic valve implantation. JACC Cardiovasc Interv 2012;5:489-96.

10. Alfredsson J, Stebbins A, Brennan JM, et al. Gait speed predicts 30-day mortality after transcatheter aortic valve replacement: results from the Society of Thoracic Surgeons/American College of Cardiology Transcatheter Valve Therapy Registry. Circulation 2016;133:1351-9.

11. Osnabrugge RL, Speir AM, Head SJ, et al. Performance of EuroSCORE II in a large US database: implications for transcatheter aortic valve implantation. Eur J Cardiothorac Surg 2014;46:400-8.

12. Piazza N, Wenaweser P, van Gameren M, et al. Relationship between the logistic EuroSCORE and the Society of Thoracic
Surgeons Predicted Risk of Mortality score in patients implanted with the CoreValve ReValving system-a Bern-Rotterdam Study. Am Heart J 2010;159:323-9.

13. Kappetein AP, Head SJ, Genereux P, et al. Updated standardized endpoint definitions for transcatheter aortic valve implantation: the Valve Academic Research Consortium-2 consensus document. J Thorac Cardiovasc Surg 2013;145:6-23.

14. Tse L, Bowering JB, Schwarz SK, et al. Postoperative delirium following transcatheter aortic valve implantation: a historical cohort study. Can J Anaesth 2015;62:22-30.

15. Eide LS, Ranhoff AH, Fridlund B, et al. Comparison of frequency, risk factors, and time course of postoperative delirium in octogenarians after transcatheter aortic valve implantation versus surgical aortic valve replacement. Am J Cardiol 2015;115:802-9.

16. Abawi M, Nijhoff $F$, Agostoni $P$, et al. Incidence, predictive factors, and effect of delirium after transcatheter aortic valve replacement. JACC Cardiovasc Interv 2016;9:160-8.

17. Inouye SK, Westendorp RG, Saczynski JS. Delirium in elderly people. Lancet 2014;383:911-22.

18. Leslie DL, Marcantonio ER, Zhang Y, et al. One-year health care costs associated with delirium in the elderly population. Arch Intern Med 2008;168:27-32.

19. Leung JM, Tsai TL, Sands LP. Brief report: preoperative frailty in older surgical patients is associated with early postoperative delirium. Anesth Analg 2011;112:1199-201.

20. Jung $P$, Pereira MA, Hiebert $B$, et al. The impact of frailty on postoperative delirium in cardiac surgery patients. $J$ Thorac Cardiovasc Surg 2015;149:869-75.e1-2.

21. Amrock LG, Deiner S. The implication of frailty on preoperative risk assessment. Curr Opin Anaesthesiol 2014;27:330-5.

22. Folstein MF, Folstein SE, McHugh PR. "Mini-mental state". A practical method for grading the cognitive state of patients for the clinician. J Psychiatr Res 1975;12:189-98.

23. Koster S, Hensens AG, Schuurmans MJ, et al. Risk factors of delirium after cardiac surgery: a systematic review. Eur $J$ Cardiovasc Nurs 2011;10:197-204.

24. Guenther U, Theuerkauf N, Frommann I, et al. Predisposing and precipitating factors of delirium after cardiac surgery: a prospective observational cohort study. Ann Surg 2013;257:1160-7.

25. Smulter N, Lingehall HC, Gustafson Y, et al. Delirium after cardiac surgery: incidence and risk factors. Interact Cardiovasc Thorac Surg 2013;17:790-6.

26. Osse RJ, Fekkes D, Tulen $\mathrm{JH}$, et al. High preoperative plasma neopterin predicts delirium after cardiac surgery in older adults. J Am Geriatr Soc 2012;60:661-8.

27. Brown $\mathrm{CH}$. Delirium in the cardiac surgical ICU. Curr Opin Anaesthesiol 2014;27:117-22.

28. Wilbring M, Tugtekin SM, Alexiou K, et al. Transapical transcatheter aortic valve implantation vs conventional aortic valve replacement in high-risk patients with previous cardiac surgery: a propensity-score analysis. Eur J Cardiothorac Surg 2013;44:42-7.

29. Kalisvaart KJ, de Jonghe JF, Bogaards MJ, et al. Haloperidol prophylaxis for elderly hip-surgery patients at risk for delirium: a randomized placebo-controlled study. J Am Geriatr Soc 2005;53:1658-66. 